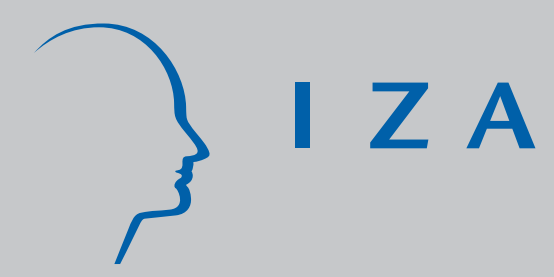

IZADP No. 2171

Shortening the Potential Duration of Unemployment Benefits Does Not Affect the Quality of Post-Unemployment J obs: Evidence from a Natural Experiment

J an C. van Ours

Milan Vodopivec

J une 2006 


\title{
Shortening the Potential Duration of Unemployment Benefits Does Not Affect the Quality of Post-Unemployment Jobs: Evidence from a Natural Experiment
}

\author{
Jan C. van Ours \\ Tilburg University, CentER, CEPR \\ and IZA Bonn \\ Milan Vodopivec \\ World Bank and IZA Bonn
}

Discussion Paper No. 2171

June 2006

IZA

P.O. Box 7240

53072 Bonn

Germany

Phone: +49-228-3894-0

Fax: +49-228-3894-180

Email: iza@iza.org

Any opinions expressed here are those of the author(s) and not those of the institute. Research disseminated by IZA may include views on policy, but the institute itself takes no institutional policy positions.

The Institute for the Study of Labor (IZA) in Bonn is a local and virtual international research center and a place of communication between science, politics and business. IZA is an independent nonprofit company supported by Deutsche Post World Net. The center is associated with the University of Bonn and offers a stimulating research environment through its research networks, research support, and visitors and doctoral programs. IZA engages in (i) original and internationally competitive research in all fields of labor economics, (ii) development of policy concepts, and (iii) dissemination of research results and concepts to the interested public.

IZA Discussion Papers often represent preliminary work and are circulated to encourage discussion. Citation of such a paper should account for its provisional character. A revised version may be available directly from the author. 


\section{ABSTRACT}

\section{Shortening the Potential Duration of Unemployment Benefits Does Not Affect the Quality of Post-Unemployment Jobs: Evidence from a Natural Experiment ${ }^{*}$}

This paper investigates how the potential duration of unemployment benefits affects the quality of post-unemployment jobs. It takes advantage of a natural experiment introduced by a change in Slovenia's unemployment insurance law that substantially reduced the potential benefit duration. Although this reduction strongly increased job finding rates, the quality of the post-unemployment jobs remained unaffected: the paper finds that the law change had no effect on either the type of the contract (temporary vs. permanent), the duration of the postunemployment jobs, or the wage earned in this job.

JEL Classification: C41, H55, J64, J65

Keywords: unemployment insurance, potential benefit duration, job separation rates, post-unemployment wages

Corresponding author:

Jan C. van Ours

Department of Economics

Tilburg University

P.O. Box 90153

5000 LE Tilburg

The Netherlands

Email: vanours@uvt.nl

\footnotetext{
* The authors wish to thank The National Employment Office of Slovenia, The Statistical Office of Slovenia and the Pension and Disability Fund of Slovenia for providing the data used in the study. Jakob Tomse provided excellent assistance in setting up the data sets. Support form the World Bank research project "Incentive Effects of UI systems in Transition Countries" (RF-P087059-RESEBBRSB) is gratefully acknowledged.
} 


\section{Introduction}

The impact of unemployment benefits on the quality of post-unemployment jobs is theoretically ambiguous and empirically not sufficiently researched. According to job search theory, an increase in the level of benefits raises the reservation wage at the beginning of the covered unemployment spell, thus leading to post-unemployment wage gains (and gains in stability and other aspects of newly found jobs). Another line of reasoning that also suggests that unemployment benefits increase the probability of finding a job and/or the quality of the job points to the fact that such payments increase the resources available for job search, thereby facilitating a more efficient job-matching process. ${ }^{1}$ On the other hand, by introducing moral hazard, a higher level of benefits may depress job search intensity and may just prolong unemployment without improving the quality of post-unemployment jobs. ${ }^{2}$ Skill obsolescence and loss of human capital resulting from longer unemployment spells may also contribute to worse post-unemployment outcomes.

There is no compelling evidence that unemployment benefits, by subsidizing job-search costs, improve job matches (Cox and Oaxaca 1990). Using U.S. data, Ehrenberg and Oaxaca (1976), Burgess and Kingston (1976), Hoelen (1977), and Barron and Mellow (1979) find a statistically significant and positive relationship between benefit levels and post-unemployment wages. Ehrenberg and Oaxaca (1976) estimate that a 10 percentage point increase in the benefit replacement rate increases post-unemployment wages by 7 percent for older men and 1.5 percent for older women. Using New Zealand data, Maani (1993) finds that a 10 percentage point increase in the benefit replacement rate is associated with a 4.5 percent increase in post-unemployment wages. Other studies show a weak or negligible effect on post-

\footnotetext{
${ }^{1}$ According to Klassen and Woolard (2001), the absence of unemployment benefits in South Africa affects household formation and residential choices in ways that are detrimental to jobfinding. The system forces the unemployed to base their location decisions on the availability of economic support generally available in rural areas, often in parental households rather than on the availability of job openings. Klassen and Woolard thus conclude that the absence of unemployment benefits may not only lower welfare of the unemployed and their dependents, but it may actually increase unemployment durations.

${ }^{2}$ Particularly credible evidence on the effects of unemployment insurance on duration of recipients spell is provided by micro-studies (for a recent summary, see Vodopivec, 2004).
} 
unemployment wages. Blau and Robins (1986) and Kiefer and Neumann (1989) find a positive but statistically insignificant relationship between benefits and earnings. Addison and Blackburn (2000) find weak evidence of improved earnings, and Classen (1977) finds no effect. Meyer (1995) finds that re-employment bonuses shorten the duration of compensated unemployment without affecting post-unemployment wages. Note that empirical testing of the effects of unemployment insurance on postunemployment earnings is complicated by the fact that it is hard to isolate the effects of changes in unemployment benefits on wages, because the factors responsible for variations in benefit generosity among recipients may also affect post-unemployment wages of recipients. Of course this also holds for other characteristics that determine the quality of job matches, i.e. the type of contract offered and the duration of postunemployment jobs.

Several studies have investigated the effects of unemployment insurance on the duration of post-unemployment jobs. One recent study finds that while the occurrence of unemployment severely reduces the duration of subsequent job tenure, the duration of unemployment has no deleterious impact - in fact, longer durations of unemployment are rewarded by longer job tenures, presumably because a longer period of job search improved worker-job match (Böheim and Taylor, 2002). But Portugal and Addison (2003) find no evidence that unemployment benefits facilitated entry into stable jobs in Portugal. Belzil (2001) using Canadian data finds a negative correlation between unemployment duration and subsequent job duration, but this correlation is mostly explained through the negative correlation between individual heterogeneity of the job finding rate and the job separation rate. Other studies include Jurajda (2002), who uses U.S. data and finds that eligibility for UI reduces workers employment durations, and Tatsiramos (2006), who uses data for ten European countries and finds that post-unemployment jobs last longer in countries with relatively generous UI.

Our paper investigates the impact of unemployment benefits on several postunemployment job characteristics and takes advantage of a change in Slovenia's UI benefit law to isolate the effects of unemployment benefits. The exceptionally rich administrative data sets on both unemployed and employed workers allow us to focus not only on post-unemployment wages, but also on the duration of subsequent employment as well as the type of contract obtained. The reform of Slovenia's unemployment benefit allows us to compare pre- and post-reform outcomes for treatment 
and control groups (the potential duration of benefits for the former changed, but for the latter stayed constant). We find that the reduction in benefit duration did not affect the quality of post-unemployment jobs taken by benefit recipients. None of the indicators for the quality of a job was negatively affected by the reform: the pre-reform distribution between fixed-term and permanent jobs stayed unchanged, as did the duration of the newly found jobs and the wages accepted in these jobs. These findings shed important additional light on the findings of our companion paper (Van Ours and Vodopivec, 2006) showing that the unemployment benefit reform resulted also in the reduction of unemployment spells. Taken together, the results show that once their potential benefit duration was reduced, the benefit recipients found a job more quickly without deterioration of the quality of the postunemployment job - an indication that the reduction of benefits reduced the moral hazard created by unemployment insurance.

This paper is set up as follows. In the next section of the paper we describe the 1998 change in Slovenias unemployment insurance system. In section 3 we present our data and explanatory variables and the formation of comparison groups. In section 4 we present our analysis of job duration, which consists of two parts. We first analyze whether the reduction in the PBD affects the distribution of employment with respect to type of jobs - temporary or permanent - and then we analyze whether this reduction affects separation rates from post-unemployment jobs. In section 5 we present the results of our analysis of post-unemployment wages, and in section 6 our conclusions.

\section{The 1998 change in the Slovenian UI system}

Formerly a part of Yugoslavia, Slovenia - a country with a population of only 2 million - became independent in 1991 and joined the European Union in 2004. Since 1995, its unemployment rate has remained remarkably stable, at a level of 6 to $7 \%$. Like OECD countries, Slovenia provides income support for the unemployed through a social insurance program that combines unemployment insurance (UI) and unemployment assistance (UA). Benefits cover the majority of employed persons, whatever their industry or occupation (the most notable exception being the selfemployed). Benefits under employment insurance are earnings related, with the 
duration of entitlement contingent on work experience and predetermined maximum and minimum levels. Benefits under UA are means-tested. They are offered to those who have exhausted their eligibility for UI (but are still unemployed) and to selected groups of other workers who do not qualify for unemployment insurance benefits. Benefits are financed mostly by the budget, with token contributions paid by employers and workers.

Registering as unemployed with an employment office entitles workers not only to cash benefits but also to other services: information about and referrals to job vacancies; vocational counseling and assistance with social and psychological adaptation; reimbursement for eligible travel and medical check-up expenses associated with job search; and the opportunity to participate in a host of active labor market programs. The latter include training courses, job-search assistance, job clubs, self-employment programs (offering free advisory programs and financial assistance), and hiring subsidies (some available only to the long-term unemployed). One obvious reason to remain registered after unemployment insurance benefits run out is to collect unemployment assistance, but there are many reasons why unemployed workers tend to remain registered for the full period of unemployment.

Slovenia in October 1998 reformed its unemployment benefit system. Arguably the most significant change was the reduction of the potential duration of benefits. Under the new system, the length of the UI entitlement period was shortened roughly by half for most groups of recipients. Before the reform, for example, workers with 5 to 10 years of work experience were eligible for 9 months of benefits, and workers with 10 to 15 years of experience were eligible for 12 months. After reform, both groups were eligible only for 6 months of benefits. A notable feature of reform was that different groups of beneficiaries were treated differently - a trait we take advantage of in testing reform's effects.

Reform also called for several measures aimed at speeding up benefit recipients' reemployment, including improvement in employment services, the obligatory preparation of a re-employment plan for each benefit recipient, and more frequent contact between counsellors and recipients. Furthermore, reform broadened the definition of a suitable job (after 4 months, the unemployed could be offered worse-paying jobs or jobs requiring a substantial commute) and introduced stiffer sanctions for refusing job offers. It also called for stricter monitoring of eligibility. Benefit recipients had to make themselves available to employment office counsellors several hours a day. 
For the first time, inspectors (a special arm of employment offices) would check to see if benefit recipients were in fact unemployed (among other things, by paying home visits to benefit recipients) and actively searching for a job.

\section{Data}

\subsection{Data sources}

The analysis is based on administrative records of unemployment spells for the recipients of unemployment benefits, as well as of their post-unemployment employment spells, for all unemployment spells that started during August 1, 1997 - July 31, 1998 and during the period January 1, 1998 - December 31, 1999 (with censoring on December 31, 2001). The following data sets were used:

- The data set on registered unemployed is from the National Employment Office of Slovenia. For each spell, it contains starting and ending dates of registered unemployment, destination of exit, and information on the receipt of unemployment insurance benefits (starting and ending date of the eligibility and actual ending date of the receipt). Personal and family characteristics of recipients are also included.

- The work history data set is from the Statistical Office of Slovenia. For all formal sector workers, the data includes information about their employment spells. The data are obtained from social insurance records and contain information on the starting and ending date, the type of appointment, occupation, and personal characteristics (gender, age, education).

- The workers' earnings data set is from the Pension and Disability Fund and contains information on earnings associated with each employment spell of workers employed in the formal sector. For each year (or part of the employ-

ment spell within a year) the information collected includes the amount of earnings, the number of hours worked in regular time and overtime, and the starting and ending date of the earnings period.

The data sources provide exceptionally rich and high quality information. First, they provide a complete coverage - all registered unemployed in the selected period 
were included. For the analysis, we selected a random sample of about 6 percent of spells. Second, being of administrative nature, the information is free of problems typically faced by survey data (such as non-response and interviewer bias). Third, by combining information about unemployment and subsequent employment spells, the information at our disposal not only covers the whole unemployment spell, but it also contains accurate information about the timing of transitions from unemployment to employment. In contrast to many studies using administrative data on unemployment spells where information about the job-finding date is based on unreliable reporting of unemployed workers themselves (as they have little incentive to do so), we have independent information about the start of post-unemployment job reported by employers. And fourth, we have the information about wages the unemployed earn in their post-unemployment jobs.

\subsection{Formation of comparison groups}

One feature worth exploiting in setting up the empirical analysis is the fact that the change in the Slovenian benefit law introduced different rules for different groups of unemployed. This allows us to disentangle the effects of changing the potential duration of benefits from the effects generated by changes in labor market conditions (such as a general increase in demand for labor), other policy changes, or a combination of these factors. We adhere to the "difference in differences" approach: We compare outcomes before and after the reform - exploiting the exogenous variation in potential benefit durations introduced by the reform - and compare outcomes for a natural control group to outcomes for several treatment groups. In short, we exploit specific design features of the changes in UI law. Note that another feature of the Slovenian UI system - that PBDs vary across groups of workers - does not identify unambiguously the relationship between PBD and quality of post-unemployment jobs. According to the law, individuals with longer work experience are entitled to longer PBD. But individuals with a longer work history are typically older, so if they would find better jobs this could be attributed not only to their longer PBD but also to their work experience.

Our basic strategy is to compare the quality of post-unemployment jobs before and after the law changed. The legislative change provides an exogenous variation in PBD. However, to be able to unambiguously identify causality underlying po- 
tential changes in the quality of post-unemployment jobs, we cannot rely solely on the exogenous variation of PBD introduced by the change in UI law. Even if we observe, for example, that shortened PBD is associated with changes in the quality of post-unemployment jobs, we cannot rule out the effects of changes in underlying conditions in the labor market (perhaps as a consequence of the business cycle). Fortunately, in our case the legislative change introduced different rules for different groups of unemployed workers, and left the PBD of one group (workers employed less than a year and a half) unchanged. The legislative design allowed us to form one control group (members for whom the PBD has not changed) and four treatment groups (whose members were subject to different PBD before and after the law changed). We assume that the relative effect of changes in labor market conditions on the job-finding rate is the same or similar for all categories of workers.

In general, one treatment group suffices, but the natural presence of four treatment groups makes our conclusions more convincing. One could object, claiming that changes in underlying labor market conditions could affect a control and a single treatment group differently. But such an objection becomes untenable once there are multiple treatment groups with different changes in PBD.

So our empirical analysis rests on data about five groups of unemployed workers: one control group and four treatment groups. Within each group, some unemployed started to collect benefits before the law changed, and some after. Had the law not changed, all members of a group would be entitled to the same PBD. Because some of the recipients in a group registered after the law changed, their entitlement was much reduced in duration. Of course, the exception is the control group for whom the PBD stayed unchanged.

For the five groups we consider in our analysis 'old' and 'new' benefit entitlements are presented in Table 1. The first group has limited work experience (up to 18 months) and it is also the only group of which the potential benefit duration has not changed - it was kept at 3 months. For the second group, which has a work experience of 1.5-5 years, the maximum benefit duration has been reduced from 6 to 3 months. All the other groups are also confronted with a reduction of the maximum benefit duration. Implicitly, the formation of groups is also strongly correlated with age. The older workers are, the more work experience they have and the longer their potential benefit duration when they loose their job.

To avoid selectivity in the inflow into unemployment around the date of the 
introduction of the new system our sample concerns the inflow into unemployment over the period August 1, 1997 - July 31, 1998 and inflow over the period January 1, 1998 - December 31, 1999. Because both time periods cover a year of inflow we do not have to worry about seasonal differences in the composition of the inflow.

Table 1 shows how the change in the PBD affected median unemployment durations. For the group of workers eligible to 3 months of $\mathrm{PBD}$ before and after the change of the benefit law, the median unemployment duration was reduced by 0.4 months, for males, and by 0.9 months, for females. For other groups of workers, the PBD after the change of the law was reduced, and the median unemployment durations were reduced more strongly than for the group with the unchanged PBD. For example, for the group for which the PBD was reduced from 18 to 9 months, the median unemployment duration was reduced by 4.1 months, for males, and by 8.2 months, for females. Two conclusions emerge: first, the median unemployment durations for females are longer than for males, and, second and most important, the reduction in median unemployment duration is stronger, the more the PBD is reduced. ${ }^{3}$

\subsection{Definition of variables}

The focus in the analysis is on the quality of the post-unemployment job. The analysis is done separately for males and females to account for possible differences in labor market behavior. In addition to this distinction by gender the effect of the following personal characteristics are taken into account:

- Previous work experience; represented by eligibility groups dummy variables: 1.5-5 years, $5-10$ years, $10-15$ years, $15-20$ years; reference group: $<1.5$ years

The effect of previous working experience may also reflect the effect of PBD since both are strongly correlated. Nevertheless due to the change in the system of UI benefits we can distinguish between the effect of previous working experience - and variables correlated with this experience - and the effect of PBD because conditional on previous working experience we have information for different PBD's. Concerning the changes in the unemployment benefit system the following variables are relevant:

\footnotetext{
${ }^{3}$ See for more details Van Ours and Vodopivec (2006)
} 
- Reduction of PBD; dummy variables for the reduction in the PBD: to 3 months, to 6 months, to 9 months; reference group: no reduction in PBD

- After benefits expiration; dummy variable if individual left unemployment after his/her benefits expired; reference group: individual left unemployment before his/her benefits expired

- End of benefit spike; dummy variable if individual left unemployment in the month of benefit expiration; reference group: individual left unemployment in a different month

- Month of unemployment spell in which a job was found; dummy variables for the months $2,3,4,5,6,7-9,10-12,13-18$, and 18+; reference group: month 1 .

Finally, there are other personal characteristics:

- Age: continuous variable

- Education: dummy variables, Education2 (elementary school), Education3 (vocational school), Education4 (high school or more); reference group: unfinished elementary school

- Family situation: dummy variables, Family1 (1 dependent family member), Family2 (more than 1 dependent family member); reference group: no dependent family members

- Ill health: Dummy variable derived from information obtained by employment office councilors from interviews with benefit recipients

These characteristics are expected to affect the quality of the post-unemployment jobs in various ways, which will be discussed in more detail below. Because labor market conditions after the change of the law may have been different from before the quality of the post-unemployment job may have been affected by this. Therefore, we also introduce a dummy variable "After change of law" when the inflow into unemployment took place in the calendar year 1999. ${ }^{4}$ We want to disentangle

\footnotetext{
${ }^{4}$ The reference group $=$ individuals becoming unemployed in the period July 1, 1997 - June 30, 1998.
} 
the effect of the labor market conditions from the effect of the change in the law on benefit entitlement. Note that our identifying assumption is that the effect of the labor market conditions is the same for every worker, in particular for every entitlement group. Since the reference entitlement group did not face a change in entitlement period the 'after the change of law' dummy variable captures the effect of the business cycle and policy changes other than the reduction in PBD.

\section{The nature of post-unemployment jobs}

If there is an effect of the changes in PBD on the durations of the post-unemployment job it may be because there is a shift in the distribution between fixed-term and permanent jobs or because the average job durations decrease within each category. We investigate both possibilities, starting with the distribution of type of jobs.

\subsection{Type of contract}

Table 1 presents information about the share of job finders that got a permanent job. As shown, for males especially those with a short work experience are less likely to get a permanent job after the reform of the benefit system. On the other hand, experienced workers are more likely to get a permanent job after the policy change. On average there is a small increase of $1.1 \%$ in the share of males that get a permanent job after they left unemployment. There does not seem to be a relationship between the declines in the PBD and the share of permanent jobs. For the males for which the PBD was reduced from 12 to 6 months or from 18 to 9 months there is even an increase in the share of permanent jobs found. For females there is an average decline of $3.7 \%$ point in the share that gets a permanent job. For females for which there is no change in PBD there is a small increase in the probability to find a permanent job while for females for which the PBD was reduced there is a decline in the probability to find a permanent job. So, for females it could be that the change in the benefit law affected behavior of unemployed job seekers in the sense that after a reduction of the PBD they are more likely to accept a fixed-term contract.

However, the transitions from unemployment to permanent and temporary jobs 
may not only be influenced by PBD but also by personal characteristics, the state of the labor market, and the duration of unemployment. We investigate this in detail by allowing each of these variables to affect the job finding rates. The transition rate to a job of type $u$ at unemployment duration $t$ conditional on observed characteristics $x$ can be specified as

$$
\theta_{u}(t \mid x)=\exp \left(\beta_{u} x+\varphi_{u}(t)+\psi_{u}(t)\right) \text { for } u=p, q
$$

where $\beta_{u}$ is a vector of parameters representing the effect of personal characteristics and $u$ can have two values: $p=$ permanent, $q=$ temporary. Furthermore, $\varphi_{u}(t)$ represents duration dependence in the transition rates

$$
\varphi_{u}(t)=\Sigma_{k} \mu_{u, k} I_{k}(t)
$$

where the $\mu$-parameters describe the stepwise duration dependence with $k(=1, \ldots, 10)$ as a subscript for the ten duration intervals: 1, 2, 3, 4, 5, 6, 7-9, 10-12, 13-18, 18+ months. For reasons of normalization we impose $\mu_{s, 1}=0$. Finally, $\psi_{u}(t)$ represents the effects of changes in the benefit system with

$$
\psi_{u}(t)=\delta_{1 j} I_{j}(t)+\delta_{2} I_{p}(t)+\delta_{3} I_{s}(t)
$$

where $I_{j}(j=1,2,3)$ is an indicator of the PBD after the policy change $(3,6$, or $9), I_{p}$ is an indicator of the duration period after benefit expiration, and $I_{s}$ is an indicator for the month of benefit expiration $(s=3,6,9,12,18)$. The $\delta$ parameters indicate the incentive effects: the $\delta_{1 j}(j=1,2,3)$ measure the pre-expiration effects, $\delta_{2}$ measures the post-expiration effect, and $\delta_{3}$ indicates the size of the spike in the month benefits expire. Note that we can identify the $\delta_{1 j}$ because of the "natural experiment" character of the change in the benefit law. Note too that we can identify $\delta_{2}$ because benefits expire at different durations of unemployment. If they all expired at the same duration we could not distinguish the post-expiration effect from duration dependence. The same holds for the spike. We can identify the spike because it occurs at different unemployment durations.

We are not interested per se in the parameter estimates that determine the transitions to temporary or permanent jobs but we want to know whether the distribution between the two types of jobs is affected by the change in the benefit law. From equation (1) we derive that the probability that the post-unemployment job 
is a permanent one equals

$$
\operatorname{Prob}(u=p \mid x, t)=\frac{\theta_{p}(t \mid x)}{\theta_{p}(t \mid x)+\theta_{q}(t \mid x)}=\frac{\exp (\psi(x, t))}{1+\exp (\psi(x, t))}
$$

which has a logit specification with $\psi(x, t)=\left(\beta_{p}-\beta_{q}\right) x+\psi_{p}(t)-\psi_{q}(t)+\varphi_{p}(t)-\varphi_{q}(t)$.

The parameters are estimated with Maximum Likelihood and presented in Table 2. This table shows that experience is important for males. Workers with little working experience have a significant smaller probability to find a permanent job. These are also the workers with a short PBD of three months. Nevertheless, Table 2 also shows that none of the indicators of PBD reduction has a significant effect on the distribution of the type of jobs, so the experience effect for males is apparently not related to the PBD. For females neither experience nor PBD reduction have an effect on the probability to find a permanent job. The 'after benefit expiration' variable has a positive effect on the probability to find a permanent job, but only for males this effect is significantly different from zero at conventional levels of significance. The 'end of benefit spike' has a large and significant effect on the probability to find a permanent job. This could be a result of a strategic behavior on the part of jobseekers (and their prospective employers) when beneficiaries find jobs beforehand and either agree on starting the job after benefit expiration, or working without a contract while simultaneously receiving UI benefits. Note that under the latter option, the employer saves on paying social security contributions, and the worker 'double-dips' - with the penalties for doing so being small.

Finally, Table 2 shows that there is a positive correlation between unemployment duration and the probability to find a permanent job. Unemployed workers that take more time to find a job are less likely to end up in a fixed-term contract. As shown higher educated workers are more likely to find a permanent job than low educated workers. The size of the family reduces the likelihood of transitions to permanent jobs for women, but not for men. This suggests that employers prefer to employ women with children under a fixed-term contract rather than under the permanent one, probably because these women are more likely to take sick leaves. Ill-health has negative effect on the probability to find a permanent job for males but not for females. Age is important for females but not for males. ${ }^{5}$ For females the probability to find a permanent job is generally lower after the change in the benefit law.

\footnotetext{
${ }^{5}$ Note that age and experience are heavily correlated.
} 
So, overlooking all the incentive effects generated by the PBD reductions it is clear that these reductions have not led to unemployed workers being 'forced' into temporary jobs. The fact that unemployed are more likely to find a job in the month of benefit expiration and the fact that the share of permanent jobs is relatively high points more to opportunistic behavior than to restricted behavior.

\subsection{Duration of the job}

In order to analyze the duration of post-unemployment jobs we exploit hazard rate analysis where job separation rates are the focus of interest. When calculating job separation rates information about completed and on-going job spells may be used, where the latter are considered to be right-censored job durations. Some information concerning job separation rates is given in Figures 1 and 2. For males there are clear spikes in the separation rate from temporary jobs at 3, 6, 12 and especially 9 months. Also for females such quarterly spikes are present, but there is no such a pronounced spike at 9 months. For males the separation rates from temporary jobs are somewhat higher than for females. After 18 months 50-55\% of the males still has a job while for females this is 55-60\%. The patterns for the job separation rates from permanent jobs are not very exciting with rates that are usually less than $1 \%$ per month. After 18 months $90 \%$ of the males and females are still having a job.

To investigate the determinants of job separations we estimate a mixed proportional hazard model (MPH) where the job separation rate at employment duration $t_{e}$ conditional on observed variables $z$ and unobservable characteristics $v$

$$
\theta_{s}\left(t_{e} \mid z, v_{s}\right)=\exp \left(\beta_{s} z+\Sigma_{k} \mu_{s, k} I_{k}\left(t_{e}\right)+v_{s}\right) \text { for } s=p, q
$$

where $z$ now includes personal characteristics and characteristics of the unemployment insurance pertaining to the unemployment spell that ended when a person started the current $\mathrm{job}^{6}, \beta_{s}$ is a vector of parameters, $s$ an indicator of the type of job ( $p=$ permanent, $q=$ temporary) and the $\mu_{s}$ parameters represent stepwise individual duration dependence in the separation rates. Again, for reasons of normalization we impose $\mu_{s, 1}=0$. The unobserved components are assumed to be randomly distributed following a discrete distribution with two points of support $p_{1}$ and $p_{2}$, with

\footnotetext{
${ }^{6}$ Note that different from before these characteristics are not duration-dependent but fixed at the start of the employment spell.
} 
$\operatorname{Pr}\left(v_{s}=v_{s, a}\right)=p_{s, 1}$ and $\operatorname{Pr}\left(v_{s}=v_{s, b}\right)=p_{s, 2}$ where the discrete distribution is supposed to have a logit specification with $p_{s, i}=\frac{e^{\alpha_{s, i}}}{\Sigma_{i=1}^{2} e^{\alpha_{s, i}}}, i=(1,2)$, and $\alpha_{s, 2}=0$ is used for normalization. The conditional density functions of the completed job durations can be written as

$$
f_{s}\left(t_{e} \mid z, v_{s}\right)=\theta_{s}\left(t_{e} \mid z, v_{s}\right) \exp \left(-\int_{0}^{t_{e}} \theta_{s}\left(c \mid z, v_{s}\right) d c\right)
$$

and we remove the unobserved components by taking expectations:

$$
f_{s}\left(t_{e} \mid z\right)=E_{v_{s}}\left[f_{s}\left(t_{e} \mid z, v_{s}\right)\right]
$$

The parameters are again estimated with the method of maximum likelihood and presented in Table 3. For males the effect of experience is negative indicating that more experience leads to longer post-unemployment jobs. Again, because experience and PBD are correlated this could suggest that a longer PBD allows a worker to invest in search and find a better job. However this would be a wrong conclusion. As shown as far as permanent jobs are concerned there are no positive effects of the PBD reductions. Also, there is no effect of benefit expiration. Unemployed that enter a job in the month of their benefit expiration have no higher separation rates from permanent jobs. Only for males in temporary jobs there is a positive effect of PBD reduction - from 6 months to 3 months, and from 18 months to 9 months. For males that accept a temporary job in the month of benefit expiration the job separation rate is even lower than for other unemployed. For females in temporary jobs none of the benefit related variables has a significant effect on the job separation rate. Separation rates from permanent jobs are not duration dependent. For temporary jobs there is some duration dependence. For males temporary jobs that last longer than a year have lower separation rates. For females there is no such effect.

Some of the personal characteristics affect the job separation rates, usually irrespective of gender and type of job. Age has a positive effect on the job separation rate, education has a negative effect. As far as permanent jobs are concerned the month of unemployment in which the job is found is irrelevant with respect to the separation rate. Apparently, searching longer does not lead to better matches in terms of job duration. For temporary jobs there is a negative effect of the unemployment duration but this is clearly non-monotonous. It is especially jobs found in the first month of unemployment that have a higher separation rate. Finally, only for females in temporary jobs we find evidence for the presence of unobserved 
heterogeneity. Conditional on observed characteristics and the elapsed duration of the (temporary) job there is a group of $76 \%$ that has a positive separation rate and a group of $24 \%$ that has a zero separation rate. It could be that for some of the females temporary jobs are not as temporary as it seems. Alternatively it could be that our period of observation is too short to establish small separation rates.

As discussed in the introduction, the relationship between potential benefit duration and the duration of the first job may be affected by correlation between unobservables in the job finding rate and the job separation rate. To investigate this we estimate a bivariate duration model with correlated error terms, separately for males and females and separately for temporary jobs and permanent jobs. The job separation rate is specified as in (5) before, while the job finding rate is specified as in (1) introducing unobservable characteristics $w$

$$
\theta_{u}\left(t \mid x, w_{u}\right)=\exp \left(\beta_{u} x+\varphi_{u}(t)+\psi_{u}(t)+w_{u}\right) \text { for } u=p, q
$$

We allow for the possibility that the unobservables in both the job finding rate and the job separation rate are from discrete distributions with two points of support. Thus, the joint distribution may have four points of support $p_{1}, p_{2}, p_{3}$, and $p_{4}$ (ignoring the subscripts for temporary and permanent jobs) with $\operatorname{Pr}\left(v=v_{a}, w=\right.$ $\left.w_{a}\right)=p_{1}, \operatorname{Pr}\left(v=v_{a}, w=w_{b}\right)=p_{2}, \operatorname{Pr}\left(v=v_{b}, w=w_{a}\right)=p_{3}$, and $\operatorname{Pr}(v=$ $\left.v_{b}, w=w_{b}\right)=p_{4}$. The discrete distribution is supposed to have a multinomial logit specification with $p_{i}=\frac{e^{\alpha_{i}}}{\Sigma_{i=1}^{4} e^{\alpha_{i}}}, i=(1, . ., 4)$, and $\alpha_{4}=0$ is used for normalization. The conditional density functions of the completed durations until job finding can be written as

$$
f_{u}\left(t \mid x, w_{u}\right)=\theta_{u}\left(t \mid x, w_{u}\right) \exp \left(-\int_{0}^{t} \theta_{u}\left(c \mid x, w_{u}\right) d c\right)
$$

and we remove the unobserved components by taking expectations:

$$
f\left(t, t_{e} \mid x, z\right)=E_{v_{s}} E_{w_{u}}\left[f_{s}\left(t_{e} \mid z, v_{s}\right) \cdot f_{u}\left(t \mid x, w_{u}\right)\right]
$$

The parameters are again estimated with the method of maximum likelihood. For permanent jobs we did not find any indication of correlated unobservables. The same holds for males and temporary jobs. For females and temporary jobs we find correlated unobservables where the distribution has three points of support. We find conditional on the observed characteristics and the elapsed durations of unemployment and employment that there are three groups. The first group of 
about $70 \%$ has a positive job finding rate and positive job separation rate; the second group of about $14 \%$ has a positive job finding rate and a zero job separation rate. The third group of about $16 \%$ has a zero job finding rate. Nevertheless, the parameters of the benefit variables hardly change and therefore our main conclusions remain as they are. ${ }^{7}$

\section{$5 \quad$ Wages in post-unemployment jobs}

In addition to the effects on job durations we also analyze the effects of PBD reductions on post-unemployment wages. One of the problems with the analysis of the wages is that for many unemployed that found a job no information about the new wage (or the previous wage) is available. The records on earnings are based on merging the data from the Pension and Disability Fund with data from the Statistical Office of Slovenia, based on personal identification numbers (PINs). The merging is incomplete, because Pension and Disability Fund records sometimes only contain identifiers issued by the Fund, with PIN numbers missing. There is no reason, as far as we know, that such omissions are non-random. For new earnings, in addition, there are fewer matches because at the time of data collection (the end of 2002), some employers did not yet provide data for 2001. The deadline for submission is June of the following year, but in reality many employers submit data with a delay as large as one year. ${ }^{8}$ Only for about 4000 males and females that have found a job, information is available about their earnings. Wages are calculated as earnings divided by spell hours - taking into account the amount of overtime and the fact that overtime working hours pay $20 \%$ more. To reduce the effects of errors in earnings and hours of work we limit the wage range from 20,000 to 150,000 Slovenian Tolars. ${ }^{9}$ This reduces the sample to about 3000 males and females.

\footnotetext{
${ }^{7}$ The parameter estimates are available on request.

${ }^{8}$ The reduction of the sample size is as follows:

Males Females

Found job $\quad 6630 \quad 7245$

Earnings info $\quad 3819 \quad 4088$

$20,000<$ wage $<150.000 \quad 2973 \quad 3111$

${ }^{9}$ At the time 1 US dollar was approximately 180 Slovenian Tolars.
} 
Whether or not wage information is available may not be random but may depend on the timing of events. Due to the set-up of the workers' earnings dataset, unemployed that have searched for a long time or have entered their job recently have a smaller probability to be in the wage sample. To investigate this we assume that the availability of wage information can be specified in terms of the latent variable $y^{*}$ which is assumed to depend on explanatory variables $r$ of individual $i$ :

$$
y_{i}^{*}=\beta_{y} r_{i}+u_{i}
$$

where $y_{i}=1$ if $y_{i}^{*} \geq 0$ and $y_{i}=0$ otherwise. Furthermore, $\beta_{y}$ is a vector of parameters of interest (including a constant) and $u_{i}$ is an error term that is assumed to follow a logistic distribution so we can estimate the $\beta_{y}$-parameters with a logit model. As explanatory variables we use the duration of unemployment, whether or not the wage was measured after the change of the benefit law and whether or not the postunemployment job was temporary. The top part of the first two columns of Table 4 shows the parameter estimates. Indeed, the longer the unemployment duration the smaller the probability to have wage information. Furthermore, after the change of law the probability to have wage information is smaller. For temporary jobs the probability that wage information is present is also higher.

Table 1 provides some stylized facts about the evolution of wages. The wage increases comparing wages in post-unemployment jobs with wages in pre-unemployment jobs are smaller after the benefit reform than before. Of course this may have to do with a change in inflation. What is important is that the differences in wages changes do not seem to be related to the size in the reduction of the PBD.

Concerning the wage we assume that this depends on depends on personal characteristics $z$ of individual $i$ :

$$
\ln w_{i}=\beta_{w} z_{i}+\varepsilon_{i}
$$

where $\beta_{w}$ is a vector of parameters of interest (including a constant) and $\varepsilon_{i}$ is the error term which is assumed to follow a normal distribution. The $\beta_{w}$-parameters are estimated using Maximum Likelihood. The parameter estimates are presented in the middle and bottom part of the first two columns of Table 4. As shown experience has a positive effect on wages but the reduction of the PBD did not lead to lower wages. On the contrary, females with a PBD reduction from 18 to 9 months have a wage that is about $5 \%$ higher. Although there is no effect of benefit expiration, in the month of benefit expiration there is an average wage drop of about 
3 to $4 \%$. Therefore, at least part of the spike in the month of benefit exhaustion may be attributed to a downward adjustment of the reservation wage leading to a substantial drop in the acceptance wage.

Other interesting wage regression results are as follows. There is no clear pattern of duration dependence. Apparently, searching longer does not lead to higher wages. Moreover, education has a positive effect on the wage. Males with the highest education earn a wage that is about $12 \%$ higher than males with no education, for females the difference is even 19\%. Note that higher education commands a substantial premium (over 100 percent over non-skilled) but since we have the results conditional on previous wage the estimated effects are reduced. A surprising result is that for males age has a negative effect on the wage. This is due to the inclusion of working experience as an explanatory variable. For males the experience dummies are highly significant. For females the experience dummies are insignificant. ${ }^{10}$ Table 4 also shows that conditional on all observed characteristics the previous wage has a positive effect on the new wage. This effect is due to unobserved characteristics of the workers that are captured by the previous wage. The elasticity is 0.2 to 0.3 . If conditional on the observed characteristics the previous wage was 1 percent higher the current wage is 0.2 percent higher.

As a sensitivity analysis we investigated whether the availability of wage information was unrelated to the process that determines the wage. We assume that the availability of wage information is affected by unobserved determinants that follow a discrete distribution with two points of support. To investigate this we introduce an additional point of support $\mu_{1}$ in equation (11). The unobserved components affecting the wage of individuals are also assumed to follow a discrete distribution with two points of support. The additional point of support in the wage equation is $\mu_{2}$. We assume that there is perfect correlation between the two points of support with a mixing distribution that has a logit specification $\frac{\exp (\xi)}{1+\exp (\xi)}$. This means that conditional on the observed personal characteristics there are two types of individuals that differ in their wage (high/low) and the probability that their wage information is available (high/low). This approach allows for a general selection process which does not assume normality. The additional parameter estimates are shown in the third and fourth columns of Table 4. Indeed, the estimation results improve if we

\footnotetext{
${ }^{10}$ Note that if we omit the experience dummies for both males and females we find significant positive effect of age.
} 
allow for correlation between the random effects in wages and presence of wage information. As the bottom part of the relevant columns shows both $\mu_{1}$ and $\mu_{2}$ are positive indicating positive correlation between the random effects: for - very - low wages the probability to have wage information available is very small. As shown for males there is a probability of $37 \%\left(\frac{\exp (-0.526)}{1+\exp (-0.526)}\right)$ that the wage is low and the presence of wage information is close to zero while there is a probability of $63 \%$ that the wage is - relatively - high and on average $75 \%$ of the wages is available in the dataset. ${ }^{11}$ For females there is a probability of $44 \%\left(\frac{\exp (-0.249)}{1+\exp (-0.249)}\right)$ that the wage is low and the presence of wage information is close to zero while there is a probability of $56 \%$ that the wage is high and on average about $60 \%$ of the wages is available in the dataset. Despite of the selectivity in the presence of the wage information the parameter estimates of the wage determinants are hardly affected. This indicates that selectivity is not an important issue. ${ }^{12}$

In addition to this analysis we followed a more traditional approach assuming a normal selection process including the inverse Mill's ratio to account for possible selectivity in the available wage data. The calculation of the inverse Mill's ratio is based on a probit estimate explaining the presence of wage information for all workers; the explanatory variables are the duration of unemployment, the 'after change of law dummy' and whether or not the job is temporary. The coefficients of the Mill's ratios are insignificantly different from zero indicating that if we assume normality in the selection process potential selectivity in the availability of wage information is uncorrelated with the processes that determine the wage.

\section{Concluding remarks}

Efficiency properties of unemployment insurance are theoretically ambiguous and empirically controversial. The paper sheds light on one such a controversial aspect - the impact of unemployment benefits on the quality of post-unemployment jobs.

\footnotetext{
${ }^{11}$ Calculated using the parameter estimates presented in Table 4 and average values of the explanatory variables.

${ }^{12}$ We also investigated whether the introduction of additional mass points - allowing for less than perfect correlation between the unobservables - improves the estimates but this turned out not to be the case.
} 
Even if unemployment benefits increase the duration of unemployment spells of benefit recipients - a well established empirical fact for most UI systems - they may simultaneously improve the quality of job matches. Such evidence has important implications for the attractiveness and design of unemployment insurance systems.

Taking advantage of Slovenia's "natural experiment" of 1998 which helped to isolate the impact of unemployment benefits, the paper investigated whether the strong reduction of the potential duration of unemployment benefits affected the quality of post-unemployment jobs. If the reduction in potential benefit duration forces unemployed workers to accept lower quality jobs, than in comparison to jobs obtained under unreduced benefits, it would be more likely that the post-unemployment jobs are temporary as opposed to permanent, low paying, and short lasting. We find no evidence of such an impact: the reduction in PBD did not affect the likelihood that a person takes a temporary rather than permanent job, there is hardly any effect on the job duration as measured by the job separation rates, and post-unemployment wages were unaffected. Moreover, the month in which the benefit recipients found a job seems to have no effect on how lasting the post-unemployment job was or on its wage level.

The above findings, coupled by the findings of the companion paper (van Ours and Vodopivec 2006), strongly suggest the presence of strategic, opportunistic behavior. The companion paper demonstrates that the shortening of PBD reduced the duration of unemployment spells of benefits recipients, and the present paper that this faster job finding did not occur at the cost of quality of post-unemployment jobs, that is, that workers found jobs faster without accepting lower quality jobs in terms of stability, type of contract, and lower wages. Together, these findings imply that longer PBDs contributed to longer durations of unemployment spell of benefit recipients without improving the quality of post-unemployment jobs. Apparently, additional job search had a zero marginal productivity. Alternatively benefit recipients behaved opportunistically and did not spend additional time on job search at all, perhaps in collusion with their prospective employers.

Several other facts are also suggestive of strategic, collusive behavior. Above all, our results show that there is a significant increase in the job finding rate at the point of exhaustion (the finding of the companion paper), and that the exit to jobs at the point of exhaustion results in the disproportional acceptance of permanent jobs (for males, we found the disproportional acceptance of permanent jobs also in 
the period after the expiration benefits). A plausible explanation for these facts is that beneficiaries had found jobs beforehand and either agreed to start the job after the expiration of benefits, or started working while still receiving benefits without a formal contract, and later formalized the employment. Note that it was the suspicions of such a behavior that prompted the Slovenian legislature to amend the unemployment insurance law, and that they put in the law also the requirement that benefit recipients make themselves available for contacts by employment office counsellors and inspectors.

Finally, we note that there may be institutional, country-specific determinants of outcomes of unemployment insurance systems. Depending on the effectiveness of monitoring and enforcement of job search, the moral hazard problems in various systems may be more or less pronounced. 


\section{References}

[1] Addison, J.T. and M.L. Blackburn (2000) The Effects of Unemployment Insurance on Post-unemployment Earnings, Labour Economics 7: 21-53.

[2] Barron, J. and W. Mellow (1979) Search Effort in the Labor Market, Journal of Human Resources 4 (3): 389404.

[3] Belzil, C. (2001) Unemployment Insurance and Subsequent Job Duration: Job Matching versus Unobserved Heterogeneity, Journal of Applied Econometrics 16: 619-636.

[4] Blau, D.M. and P.K. Robins (1986) Job Search, Wage Offers, and Unemployment Insurance, Journal of Public Economics 29: 173-197.

[5] Böheim R. and M.P. Taylor (2002) The Search for Success: do the Unemployed Find Stable Employment?, Labour Economics 9: 717-735.

[6] Burgess, P.L. and J.L. Kingston (1976) The Impact of Unemployment Insurance Benefits on Reemployment Success, Industrial and Labor Relations Review 30: 25-31.

[7] Classen, K. (1977) The Effect of Unemployment Insurance on the Duration of Unemployment and Subsequent Earnings, Industrial and Labor Relations Review 30: $438-444$.

[8] Cox, J.C. and R.L. Oaxaca (1990) Unemployment Insurance and Job Search, Research in Labor Economics 11 (2): 223240.

[9] Ehrenberg, R. and R.L. Oaxaca (1976) Unemployment Insurance, Duration of Unemployment, and Subsequent Wage Gain, American Economic Review 66: 754-766.

[10] Hoelen, A. (1977) Effects of Unemployment Insurance Entitlement on Duration and Job Search Outcome, Industrial and Labor Relations Review 30: 45-50.

[11] Jurajda, S. (2002) Estimating the Effect of Unemployment Insurance Compensation on the Labor Market Histories of Displaced Workers, Journal of Econometrics 108: 227-252. 
[12] Kiefer, N.M. and G.R. Neumann (1989) Search Models and Applied Labor Economics, Cambridge: Cambridge University Press.

[13] Klassen, S. and I. Woolard (2001) Surviving Unemployment without State Support: Unemployment and Household Formation in South Africa, Working Paper CESifo No.533, Center for Economic Studies and Ifo Institute for Economic Research, Munich.

[14] Maani, S.A. (1993) Post-Unemployment Wages, the Probability of ReEmployment, and the Unemployment Benefit, New Zealand Economic Papers 27 (1): 35-55.

[15] Meyer, B.D. (1995) Lessons from the U.S. Unemployment Insurance Experiments, Journal of Economic Literature 33 (1): 91-131.

[16] Portugal, P. and J.T. Addision (2003) Six Ways to Leave Unemployment, Discussion Paper, no. 954, IZA, Bonn.

[17] Tatsiramos, K. (2006) The Effect of Unemployment Insurance on Unemployment Duration and Subsequent Employment Stability, Working Paper, IZA, Bonn.

[18] Van Ours, J.C. and M. Vodopivec (2006) How Shortening the Potential Duration of Unemployment Benefits Affects the Duration of Unemployment: Evidence from a Natural Experiment, Journal of Labor Economics 24 (2): 351-378.

[19] Vodopivec, M. (2004) Income Support Systems for the Unemployed: Issues and Options, The World Bank. 
Table 1 Quality of post-unemployment jobs by potential benefit duration of UI before and after the 1998 change of law

\begin{tabular}{|c|c|c|c|c|c|c|c|c|c|c|c|}
\hline \multirow[b]{2}{*}{ Group } & \multicolumn{2}{|c|}{ PBD (months) $\left.{ }^{a}\right)$} & \multicolumn{3}{|c|}{ Unempl. duration ${ }^{b)}$} & \multicolumn{3}{|c|}{ Permanent job $(\%)^{c)}$} & \multicolumn{3}{|c|}{ Wage change $(\%)^{d)}$} \\
\hline & Before & After & Before & After & $\Delta$ & Before & After & $\Delta$ & Before & After & $\Delta$ \\
\hline \multicolumn{12}{|l|}{ Males } \\
\hline 1 & 3 & 3 & 4.2 & 3.7 & -0.4 & 19.7 & 16.9 & -2.8 & 13.3 & 8.0 & -5.3 \\
\hline 2 & 6 & 3 & 4.7 & 3.8 & -0.9 & 27.4 & 23.0 & -4.4 & 20.6 & 10.6 & -10.0 \\
\hline 3 & 9 & 6 & 6.1 & 4.5 & -1.6 & 24.2 & 24.2 & 0.0 & 17.2 & 13.3 & -3.9 \\
\hline 4 & 12 & 6 & 7.4 & 5.0 & -2.5 & 23.4 & 27.8 & 4.4 & 15.7 & 10.4 & -5.3 \\
\hline 5 & 18 & 9 & 9.8 & 5.8 & -4.1 & 24.3 & 29.0 & 4.7 & 18.3 & 12.0 & -6.3 \\
\hline Total & & & 5.8 & 4.4 & -1.4 & 23.4 & 24.5 & 1.1 & 16.7 & 10.9 & -5.8 \\
\hline \multicolumn{12}{|c|}{ Females } \\
\hline 1 & 3 & 3 & 5.5 & 4.6 & -0.9 & 20.4 & 21.0 & 0.6 & 15.7 & 11.3 & -4.4 \\
\hline 2 & 6 & 3 & 6.4 & 4.5 & -1.9 & 23.7 & 20.2 & -3.5 & 19.8 & 14.0 & -5.8 \\
\hline 3 & 9 & 6 & 8.4 & 5.5 & -2.9 & 26.4 & 21.3 & -5.1 & 21.1 & 19.8 & -1.3 \\
\hline 4 & 12 & 6 & 11.0 & 5.5 & -5.5 & 24.2 & 18.3 & -5.9 & 20.1 & 17.0 & -3.1 \\
\hline 5 & 18 & 9 & 15.2 & 7.0 & -8.2 & 22.3 & 17.7 & -4.6 & 15.7 & 18.0 & 2.3 \\
\hline Total & & & 8.5 & 5.3 & -3.2 & 23.4 & 19.7 & -3.7 & 18.4 & 16.0 & -2.4 \\
\hline
\end{tabular}

a) Note that the formation of groups coincides with work experience (in years): group 1

$<$ 1.5; group 2: 1.5-5; group 3: 5-10; group 4: 10-15; group 5: 15-20.

b) Median duration of unemployment in months.

c) Workers finding permanent jobs as percentage of all workers finding jobs.

d) Wage increase comparing post-unemployment wage with pre-unemployment wage. 
Table 2 Parameter estimates - probability to find a permanent job ${ }^{a}$ )

\begin{tabular}{|c|c|c|}
\hline & Males & Females \\
\hline \multicolumn{3}{|l|}{ Work experience } \\
\hline $1.5-5$ years & $0.91(3.6)^{*}$ & $0.26(1.5)$ \\
\hline 5 -10 years & $0.94(3.6)^{*}$ & $0.51(2.8)^{*}$ \\
\hline $10-15$ years & $1.04(3.5)^{*}$ & $0.28(1.3)$ \\
\hline $15-20$ years & $1.13(2.9)^{*}$ & $0.12(0.4)$ \\
\hline \multicolumn{3}{|l|}{ Unemployment Insurance } \\
\hline PBD reduced to 3 months & $-0.31(0.8)$ & $0.08(0.3)$ \\
\hline PBD reduced to 6 months & $0.30(1.1)$ & $-0.01(0.0)$ \\
\hline PBD reduced to 9 months & $0.44(1.3)$ & $-0.09(0.3)$ \\
\hline After benefits expiration & $0.53(2.1)^{*}$ & $0.27(1.4)$ \\
\hline End of benefits spike & $1.67(5.1)^{*}$ & $1.31(5.8)^{*}$ \\
\hline \multicolumn{3}{|l|}{ Left unemployment in } \\
\hline Month 2 & $0.36(1.8)$ & $0.24(1.3)$ \\
\hline Month 3 & $0.08(0.4)$ & $-0.26(1.2)$ \\
\hline Month 4 & $1.00(4.4)^{*}$ & $0.36(1.7)$ \\
\hline Month 5 & $1.14(4.7)^{*}$ & $0.56(2.6)^{*}$ \\
\hline Month 6 & $0.98(3.3)^{*}$ & $0.25(1.1)$ \\
\hline Months 7-9 & $1.15(4.7)^{*}$ & $0.58(2.8)^{*}$ \\
\hline Months 10-12 & $1.64(5.2)^{*}$ & $0.63(2.6)^{*}$ \\
\hline Months 13-18 & $2.01(5.7)^{*}$ & $0.83(3.3)^{*}$ \\
\hline Months 18+ & $2.04(4.7)^{*}$ & $0.45(1.7)$ \\
\hline \multicolumn{3}{|c|}{ Other personal characteristics } \\
\hline Education2 & $0.38(1.5)$ & $1.42(3.5)^{*}$ \\
\hline Education3 & $1.08(4.4)^{*}$ & $2.18(5.4)^{*}$ \\
\hline Education4 & $2.37(8.4)^{*}$ & $2.88(7.2)^{*}$ \\
\hline Family1 & $0.13(0.7)$ & $-0.42(3.4)^{*}$ \\
\hline Family2 & $0.13(0.8)$ & $-0.35(2.9)^{*}$ \\
\hline Ill health & $-1.14(4.1)^{*}$ & $-0.22(0.7)$ \\
\hline Age/10 & $0.09(0.5)$ & $0.58(4.1)^{*}$ \\
\hline \multicolumn{3}{|l|}{ Labor market effects } \\
\hline After change of law & $-0.07(0.4)$ & $-0.28(2.1)^{*}$ \\
\hline Constant & $-4.37(7.7)^{*}$ & $-5.57(9.2)^{*}$ \\
\hline -Loglikelihood & 2501.1 & 2982.2 \\
\hline
\end{tabular}

a) Samples of 6,630 males and 7,245 females who found a job immediately after their unemployment spell; absolute t-statistics in parentheses; $a^{*}$ indicates significance at a $95 \%$ level. 
Table 3 Parameter estimates job separation rates; males and females ${ }^{a}$ )

\begin{tabular}{|c|c|c|c|c|}
\hline & \multicolumn{2}{|c|}{ Separations permanent job } & \multicolumn{2}{|c|}{ Separations temporary job } \\
\hline & Males & Females & Males & Females \\
\hline \multicolumn{5}{|l|}{ Work experience } \\
\hline $1.5-5$ years & $0.02(0.1)$ & $-0.03(0.2)$ & $-0.28(4.0)^{*}$ & $-0.05(0.6)$ \\
\hline 5 -10 years & $-0.43(2.6)^{*}$ & $-0.48(3.0)^{*}$ & $-0.32(4.7)^{*}$ & $-0.09(1.0)$ \\
\hline 10-15 years & $-0.59(2.9)^{*}$ & $-0.27(1.4)$ & $-0.46(5.9)^{*}$ & $-0.16(1.3)$ \\
\hline $15-20$ years & $-0.77(3.0)^{*}$ & $-0.27(1.0)$ & $-0.71(7.1)^{*}$ & $-0.28(1.6)$ \\
\hline \multicolumn{5}{|l|}{ Unemployment Insurance } \\
\hline PBD reduced to 3 months & $-0.26(0.8)$ & $-0.21(0.8)$ & $0.23(2.0)^{*}$ & $-0.05(0.3)$ \\
\hline PBD reduced to 6 months & $-0.06(0.3)$ & $-0.06(0.3)$ & $0.05(0.6)$ & $0.01(0.1)$ \\
\hline PBD reduced to 9 months & $-0.21(0.9)$ & $-0.58(2.2)^{*}$ & $0.22(2.2)^{*}$ & $0.11(0.7)$ \\
\hline After benefits expiration & $0.02(0.1)$ & $-0.29(1.8)$ & $0.02(0.3)$ & $0.10(1.1)$ \\
\hline End of benefits spike & $-0.13(0.8)$ & $-0.07(0.5)$ & $-0.15(2.2)^{*}$ & $-0.10(1.1)$ \\
\hline \multicolumn{5}{|l|}{ Left unemployment in } \\
\hline Month 2 & $0.16(0.8)$ & $0.25(1.3)$ & $-0.33(4.7)^{*}$ & $-0.42(3.6)^{*}$ \\
\hline Month 3 & $0.35(1.7)$ & $0.38(1.9)$ & $-0.11(1.7)$ & $-0.20(1.6)$ \\
\hline Month 4 & $0.29(1.4)$ & $0.16(0.7)$ & $-0.23(3.1)^{*}$ & $-0.34(2.5)^{*}$ \\
\hline Month 5 & $0.17(0.8)$ & $0.35(1.6)$ & $-0.04(0.5)$ & $-0.26(1.9)$ \\
\hline Month 6 & $0.14(0.6)$ & $0.19(0.8)$ & $-0.33(3.6)^{*}$ & $-0.43(2.8)^{*}$ \\
\hline Months 7-9 & $0.05(0.1)$ & $0.52(2.4)^{*}$ & $-0.27(3.3)^{*}$ & $-0.43(3.0)^{*}$ \\
\hline Months 10-12 & $-0.02(0.1)$ & $0.39(1.6)$ & $-0.22(2.2)^{*}$ & $-0.46(2.6)$ \\
\hline Months 13-18 & $-0.05(0.2)$ & $0.32(1.3)$ & $-0.18(1.7)$ & $-0.32(1.8)$ \\
\hline Months 18+ & $-0.45(1.3)$ & $0.53(1.8)$ & $-0.11(0.9)$ & $-0.01(0.1)$ \\
\hline \multicolumn{5}{|l|}{ Duration dependence } \\
\hline Month 2 & $-0.13(0.4)$ & $-0.28(1.0)$ & $0.08(0.9)$ & $0.45(4.4)^{*}$ \\
\hline Month 3 & $0.57(2.2)^{*}$ & $0.20(0.8)$ & $0.43(5.2)^{*}$ & $0.79(8.3)^{*}$ \\
\hline Month 4 & $-0.09(0.3)$ & $0.06(0.2)$ & $0.14(1.6)$ & $0.64(6.3)^{*}$ \\
\hline Month 5 & $0.18(0.6)$ & $-0.15(0.5)$ & $0.06(0.5)$ & $0.75(7.4)^{*}$ \\
\hline Month 6 & $0.19(0.7)$ & $-0.13(0.4)$ & $0.12(1.3)$ & $0.62(5.8)^{*}$ \\
\hline Months 7-9 & $0.6(0.7)$ & $-0.14(0.6)$ & $0.29(3.9)^{*}$ & $0.23(2.4)^{*}$ \\
\hline Months 10-12 & $0.27(1.1)$ & $-0.15(0.6)$ & $0.10(1.3)$ & $0.52(5.0)^{*}$ \\
\hline Months 13-18 & $-0.10(0.4)$ & $0.01(0.1)$ & $-0.63(7.5)^{*}$ & $0.33(2.7)^{*}$ \\
\hline Months 18+ & $-0.07(0.3)$ & $-0.12(0.6)$ & $-0.99(12.5)^{*}$ & $0.06(0.3)$ \\
\hline
\end{tabular}


Table 3 continued

\begin{tabular}{|c|c|c|c|c|}
\hline & \multicolumn{2}{|c|}{ Separations permanent job } & \multicolumn{2}{|c|}{ Separations temporary job } \\
\hline & Males & Females & Males & Females \\
\hline \multicolumn{5}{|c|}{ Other personal characteristics } \\
\hline Education2 & $-0.24(1.0)$ & $-0.07(0.1)$ & $-0.13(1.9)$ & $-0.11(0.7)$ \\
\hline Education3 & $-0.50(2.2)^{*}$ & $-0.29(0.6)$ & $-0.26(4.0)^{*}$ & $-0.17(1.3)$ \\
\hline Education4 & $-0.78(3.4)^{*}$ & $-0.41(0.9)$ & $-0.38(5.3)^{*}$ & $-0.35(2.7)^{*}$ \\
\hline Family1 & $-0.09(0.8)$ & $0.12(1.2)$ & $0.11(2.2)^{*}$ & $-0.10(1.7)$ \\
\hline Family2 & $-0.02(0.1)$ & $-0.05(0.4)$ & $-0.07(1.4)$ & $-0.10(1.5)$ \\
\hline Ill health & $0.59(2.8)^{*}$ & $0.42(1.6)$ & $-0.09(1.1)$ & $0.17(1.3)$ \\
\hline Age/10 & $0.45(3.8)^{*}$ & $-0.10(0.7)$ & $0.24(5.1)^{*}$ & $0.18(2.6)^{*}$ \\
\hline \multicolumn{5}{|l|}{ Labor market effects } \\
\hline After change of law & $-0.09(0.7)$ & $0.30(2.5)^{*}$ & $0.07(1.3)$ & $0.08(1.4)$ \\
\hline \multicolumn{5}{|c|}{ Unobserved heterogeneity } \\
\hline Masspoint 1 & $-8.15(17.2)^{*}$ & $-6.94(11.2)^{*}$ & $-6.48(41.2)^{*}$ & $-6.59(25.7)^{*}$ \\
\hline Masspoint 2 & $-8.15(17.2)^{*}$ & $-6.94(11.2)^{*}$ & $-6.48(41.2)^{*}$ & $-\infty$ \\
\hline$\alpha$ & - & - & - & $1.16(5.3)$ \\
\hline -Loglikelihood & $4,998.3$ & $5,290.2$ & $25,478.7$ & $26,489.6$ \\
\hline $\mathrm{N}$ & 1,587 & 1,569 & 5,043 & 5,675 \\
\hline
\end{tabular}

a) Samples of males and females who found a job immediately after their unemployment spell; absolute t-statistics in parentheses; a * indicates significance at a $95 \%$ level. 
Table 4 Parameter estimates probability of having wage information and determinants of log wages $^{a}$ )

\begin{tabular}{|c|c|c|c|c|}
\hline & \multicolumn{2}{|c|}{ No selectivity } & \multicolumn{2}{|c|}{ Possible selectivity } \\
\hline & Males & Females & Males & Females \\
\hline \multicolumn{5}{|l|}{ I. Wage info available } \\
\hline Duration/10 & $-0.013(9.8)^{*}$ & $-0.014(12.9)^{*}$ & $-0.026(6.7)^{*}$ & $-0.037(6.6)^{*}$ \\
\hline After change of law & $-0.790(15.3)^{*}$ & $-0.795(16.1)^{*}$ & $-1.670(6.4)^{*}$ & $-2.351(5.2)^{*}$ \\
\hline Temporary job & $0.366(6.0)^{*}$ & $0.327(5.4)^{*}$ & $0.677(5.7)^{*}$ & $0.651(5.0)^{*}$ \\
\hline Constant & $0.110(1.6)$ & $0.148(2.3)^{*}$ & $-5.440(12.3)^{*}$ & $-4.898(14.1)^{*}$ \\
\hline \multicolumn{5}{|l|}{ II. Log (new wage) } \\
\hline Log(old wage) & $0.246(14.2)^{*}$ & $0.210(13.0)^{*}$ & $0.251(14.7)^{*}$ & $0.215(13.3)^{*}$ \\
\hline Temporary job & $-0.007(0.7)$ & $-0.008(0.8)$ & $-0.005(0.5)$ & $-0.006(0.6)$ \\
\hline \multicolumn{5}{|l|}{ Work experience } \\
\hline $1.5-5$ years & $0.042(2.4)^{*}$ & $0.019(1.4)$ & $0.042(2.4)^{*}$ & $0.017(1.2)$ \\
\hline 5 -10 years & $0.047(2.9)^{*}$ & $0.015(1.0)$ & $0.043(2.7)^{*}$ & $0.013(0.9)$ \\
\hline $10-15$ years & $0.071(3.7)^{*}$ & $0.009(0.5)$ & $0.067(3.6)^{*}$ & $0.009(0.5)$ \\
\hline $15-20$ years & $0.123(5.0)^{*}$ & $-0.018(0.9)$ & $0.114(4.7)^{*}$ & $-0.015(0.7)$ \\
\hline \multicolumn{5}{|l|}{ Unemployment Insurance } \\
\hline PBD reduced to 3 months & $0.008(0.3)$ & $-0.010(0.4)$ & $0.009(0.3)$ & $0.002(0.1)$ \\
\hline PBD reduced to 6 months & $0.005(0.3)$ & $0.009(0.5)$ & $0.011(0.6)$ & $0.013(0.8)$ \\
\hline PBD reduced to 9 months & $0.011(0.5)$ & $0.051(2.5)^{*}$ & $0.018(0.8)$ & $0.086(2.9)^{*}$ \\
\hline After benefits expiration & $0.017(1.0)$ & $-0.006(0.5)$ & $0.024(1.8)$ & $-0.011(0.7)$ \\
\hline End of benefits spike & $-0.028(2.4)^{*}$ & $-0.019(1.5)$ & $-0.027(2.4)^{*}$ & $-0.016(1.4)$ \\
\hline \multicolumn{5}{|l|}{ Left unemployment in } \\
\hline Months 4-6 & $-0.005(0.4)$ & $0.014(1.3)$ & $-0.005(0.5)$ & $0.016(1.5)$ \\
\hline Months 7-9 & $-0.015(1.0)$ & $-0.006(0.5)$ & $-0.016(1.1)$ & $-0.007(0.5)$ \\
\hline Months 10-12 & $-0.033(1.6)$ & $0.013(0.7)$ & $-0.022(1.1)$ & $0.017(1.1)$ \\
\hline Months $12+$ & $0.019(1.0)$ & $0.034(2.0)^{*}$ & $0.020(1.1)$ & $0.033(2.0)^{*}$ \\
\hline
\end{tabular}


Table 4 continued

\begin{tabular}{|c|c|c|c|c|}
\hline & \multicolumn{2}{|c|}{ No selectivity } & \multicolumn{2}{|c|}{ Possible selectivity } \\
\hline & Males & Females & Males & Females \\
\hline \multicolumn{5}{|l|}{ Personal characteristics } \\
\hline Education2 & $0.015(0.9)$ & $0.017(0.9)$ & $0.017(1.1)$ & $0.020(1.0)$ \\
\hline Education3 & $0.056(3.5)^{*}$ & $0.066(3.5)^{*}$ & $0.057(3.5)^{*}$ & $0.069(3.6)^{*}$ \\
\hline Education4 & $0.118(6.7)^{*}$ & $0.188(9.4)^{*}$ & $0.122(6.9)^{*}$ & $0.192(9.7)^{*}$ \\
\hline Ill health & $-0.011(0.5)$ & $-0.056(2.3)^{*}$ & $-0.006(0.4)$ & $-0.060(2.4)^{*}$ \\
\hline Age/10 & $-0.023(1.8)$ & $0.030(2.8)^{*}$ & $-0.020(1.7)$ & $0.029(2.8)^{*}$ \\
\hline \multicolumn{5}{|l|}{ Labor market effects } \\
\hline After change of law & $0.030(2.2)^{*}$ & $0.039(3.2)^{*}$ & $0.018(1.1)$ & $0.035(3.0)^{*}$ \\
\hline Constant & $8.618(43.6)^{*}$ & $8.858(49.1)^{*}$ & $7.615(36.7)^{*}$ & $7.832(38.7)^{*}$ \\
\hline \multicolumn{5}{|c|}{ Unobserved heterogeneity } \\
\hline Second mass point $\mu_{1}$ & - & - & $7.278(11.3)^{*}$ & $7.921(10.0)^{*}$ \\
\hline Second mass point $\mu_{2}$ & - & - & $0.935(13.3)^{*}$ & $0.963(11.8)^{*}$ \\
\hline Probability $(\xi)$ & - & - & $-0.526(3.8)^{*}$ & $-0.249(2.5)^{*}$ \\
\hline -Loglikelihood & 4025.7 & 4286.2 & 3992.3 & 4214.0 \\
\hline $\mathrm{N}$ wage info & 2973 & 3111 & 2973 & 3111 \\
\hline $\mathrm{N}$ total & 6630 & 7245 & 6630 & 7245 \\
\hline
\end{tabular}


Figure 1: Monthly separation rates by employment duration; males

\section{a. Temporary jobs}

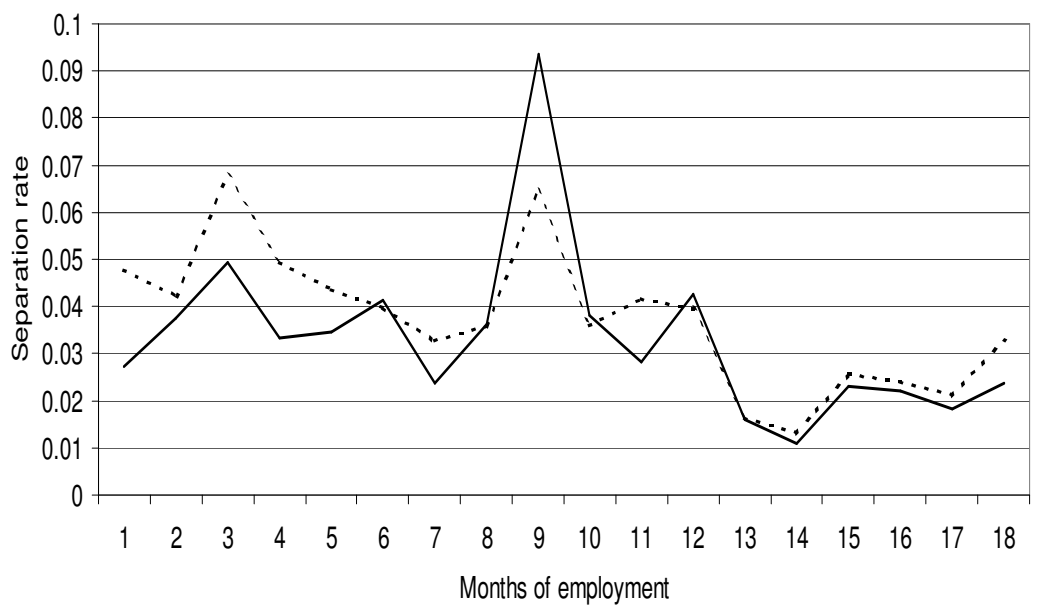

—Before -...After

b. Permanent jobs

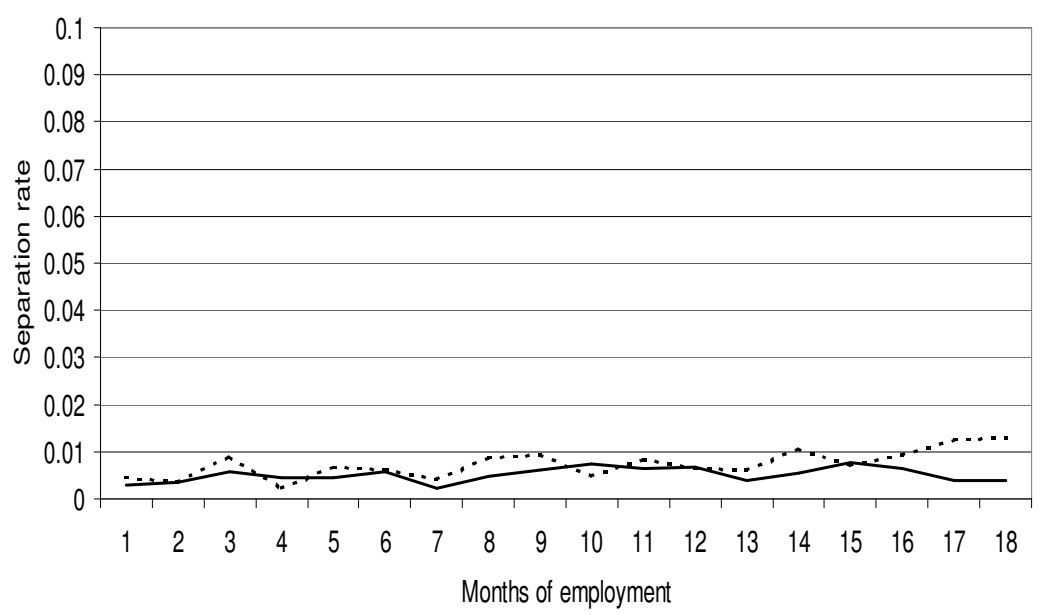

- Before ....After 
Figure 2: Monthly separation rates by employment duration; females

a. Temporary jobs

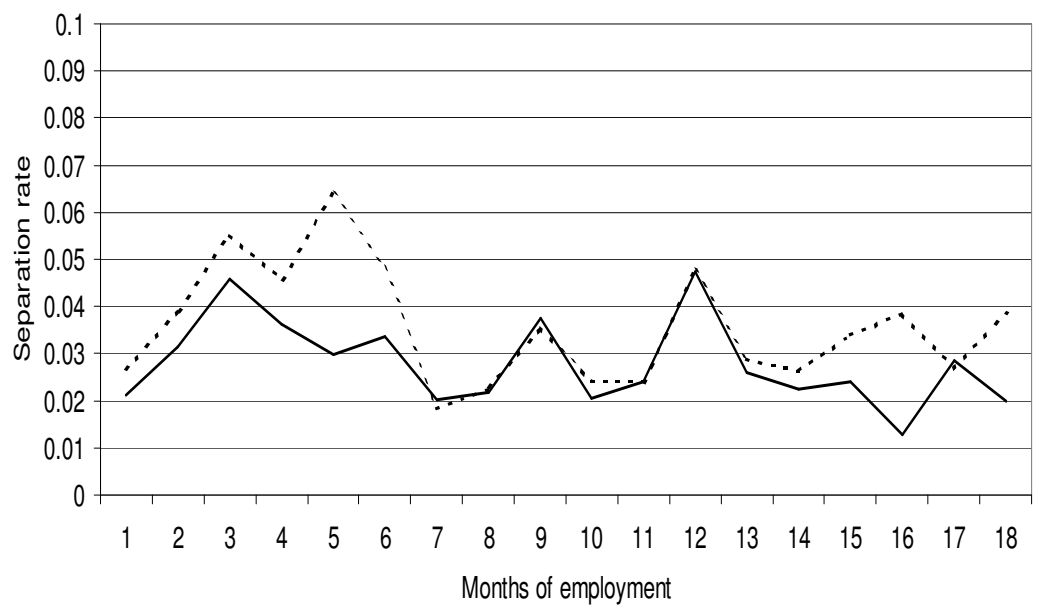

—Before -...After

b. Permanent jobs

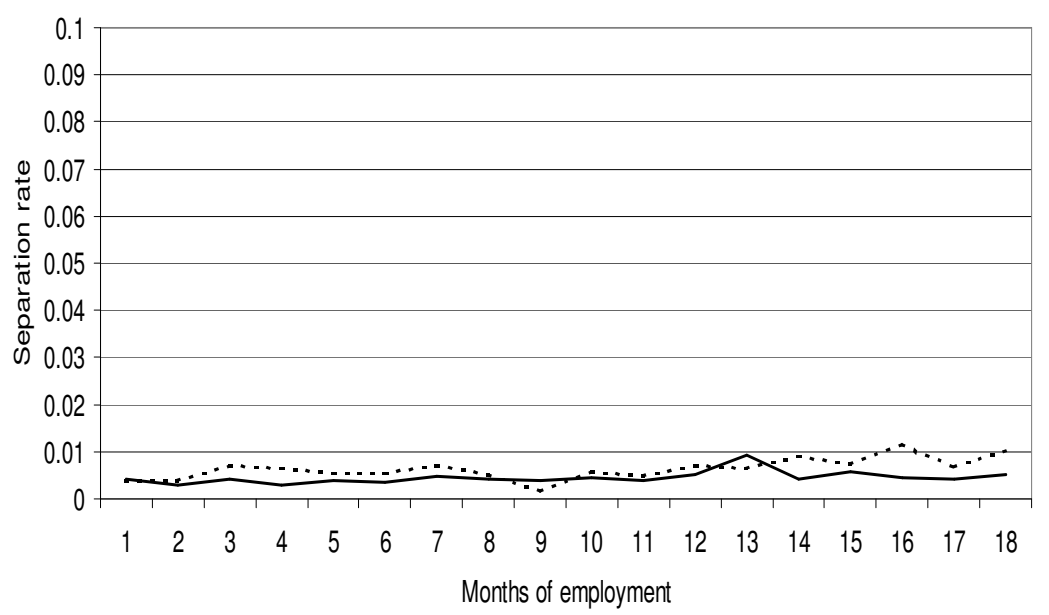

- Before ....After 